\title{
Analysis of Integrated Lecturing Event Recording System Based on Radio Frequency Identification (RFID) with Rapid Application Development (RAD) Model
}

\author{
Irfan Sudahri Damanik ${ }^{1, *}$ Eka Irawan ${ }^{2}$
}

\author{
${ }^{1}$ STIKOM Tunas Bangsa, Pematangsiantar, 21143, Indonesia \\ ${ }^{2}$ STIKOM Tunas Bangsa, Pematangsiantar, 21143, Indonesia \\ *Corresponding author.Email: irfansudahri@amiktunasbangsa.ac.id
}

\begin{abstract}
The improvement of the student learning process in higher education is of course determined by technological developments. semiconductor technology that can be integrated with various systems such as electronics and informatics. In the teaching and learning process, the implementation of conventional lecture minutes using paper media in universities has several problems. The possibility of damage, loss, human error and the use of a lot of time to recapitulate lecture minutes. By designing a system for recording lecture minutes with attendance using RFID (Radio Frequency Identification). RFID data is used to be integrated with database systems, data in the form of a unique number from the RFID card is used as a unique code for students so that when the RFID card is attached to the attendance device, the data will automatically be entered into the attendance database. This research develops information technology integrated with RFID, as well as analyzing system design using the Rapid Application Development (RAD) Model. The results of this analysis will be integrated with the Academic Information system, so that it makes it easier to solve the problem of recording lecture minutes at universities.
\end{abstract}

Keywords: RFID, RAD, Collage, Attendance, Lecture Minutes.

\section{INTRODUCTION}

Each university carries out teaching and learning process activities where one part of the activity is the lecture attendance process. Attendance can be said to be an attendance data collection which is part of existing reporting activities within an institution [1].Lecture attendance is the process of recording student attendance in following the process of teaching and learning activities carried out by the lecturer at each course meeting that is supervised by the lecturer. In carrying out the student attendance process, lecturers and academics can be said to be still ineffective because it is still done manually, namely the lecturer will do attendance by calling each student and recording it in an attendance sheet which is done repeatedly at every meeting in the teaching and learning process. This resulted in an error in the process of attendance and student attendance recap, because the data that was stored was not in a database, which was stored on sheets of paper. There are several other problems related to the manual attendance system such as consuming a lot of time for the attendance process, high error rates, difficult to recap data and unsafe data. This is what makes it important to digitize student attendance with technology.

Radio Frequency identification (RFID) technology is gaining popularity for several reasons such as being economical, saving time, saving resources, reducing labor and being easy to use [2]. The weakness of the manual attendance system mentioned above can be overcome by using RFID technology. The RFID component consists of 3 components of the RFID tag, an RFID reader and a back-end server [3]. This research is proposed to implement RFID technology in solving the problem of manual attendance methods. RFID is a technology that uses radio frequency to identify objects [4]. The sensor will perform and recognize the object in question equipped with an RFID reader and an RFID card. With an RFID card that is changed in the form of a student ID card, students can attach the RFID card and 
the RFID reader will automatically recognize the object and will store the RFID card tag data into the database as a process for student attendance in each lecture. In the development process, this RFID-based attendance system was developed using the Rapid Application Development (RAD) method. RAD is a fast software development model while maintaining product quality [5].

This proposed RFID-based attendance system will provide great benefits where student attendance data can be done automatically, so that the above problems can be solved more effectively and efficiently.

\section{METHOD}

This study applies software development using the Rapid application development (RAD) model. The software development process is divided into two main parts, namely the front end and back end and through several stages, namely planning, analysis, front end design, back-end design, implementation, and testing system. This stage can be seen in Figure 1.



Figure 1 The stages of the RAD method in developing an RFID-based attendance system

From Figure 1, the system development process starts from the initial design stage in the development of an RFID-based attendance system. This stage consists of planning the time and resources required for the development of this system so that it can be completed faster than the planning process [6]. This system is built with the PHP programming language and MySQL DBMS. The analysis is divided into two main parts, RFID tools and design, where the RFID tools used here are Plug and Play RFID readers which are integrated with a USB cable, the design process is divided into two parts, front end design and back-end design, front end design for designing. The main user interface that can be seen by students when doing the attendance process to see if the attendance process is identified, while the back-end design is used to design the appearance of the lecturer and academic user interface in seeing the attendance results and attendance recapitulation. Then the implementation stage of the design into the programming code then the testing and integration process so that it becomes an RFID based attendance software.

Front end design and back-end design This system design includes design use case diagrams, database design and layout design in this information system. The use case diagram of the attendance information system based on RFID involves 3 users, namely academics, lecturers, and students. The case diagram for the use of this RFID based attendance system is shown in Figure 2.
1) RFID Reader: Students can attach a student ID card as an RFID tag to the RFID reader to get a unique code that will display the student information concerned to enter the information into the attendance system automatically.

2) View Student Information: Students can view attendance data information based on lecture schedules made by academics.

3) View schedule: lectures can view the scheduled academic schedule and academics can add, change, and delete schedules.

4) View Student Attendance: lectures and academics can see the results of attendance that have been done by students according to schedule.

5) Student Content Management: Academic has the authority to add, modify and delete student data that has been entered into the system.

6) Content Management schedule: Academic has the authority to add, change and delete schedule data that has been entered into the system.

The next design is the database system design, the RFID based absentee system with the RAD Model has 9 data entities which include users, students, lecturers, academics, rooms, subjects, classes, matrices and attendance. The database class diagram of this system is shown in Figure 3. 




Figure 2 Use of case diagram RFID based attention system

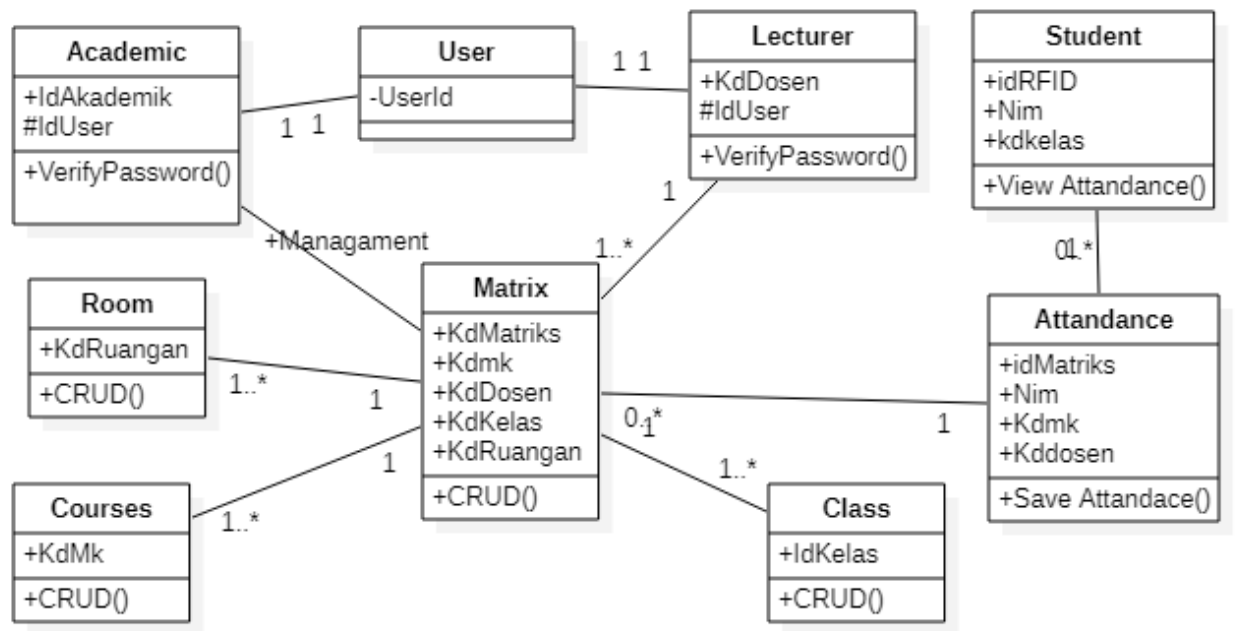

Figure 3 Class diagram RFID based attention system

1) Academics have a composition relationship with the user, where academics must log into the system.

2) Lecturers have a composition relationship with the user, where the lecturer must login to enter the system.

3) User will provide verification for academic and lecturer classes.

4) Lecturers can see lecture schedules and student attendance who do the attendance process through the system.
5) Students have a relationship between composition and attendance because when students do an attendance process.

6) From class attendance to class matrix using association to do the absences process.

7) $\mathrm{n}$ class matrix to academic class has a composition relation because all data management is in the CRUD process in class room, subject, matrix, student and lecturer class. 


\section{RESULT AND DISCUSSION}

The implementation of this RFID-based attendance system with the RAD model uses the PHP programming language and the Code Igniter framework. The results of the implementation of this system produce three parts of the user interface, namely students, lecturers and academics.

\subsection{Presenting the Results}

The users of the RFID-based attendance system are students, lecturers and academics. With this user interface users can use some of the features of this system. First, students will be faced with the initial page system where students are asked to attach their student ID card as an RFID tag to the RFID reader as shown in Figure 4.

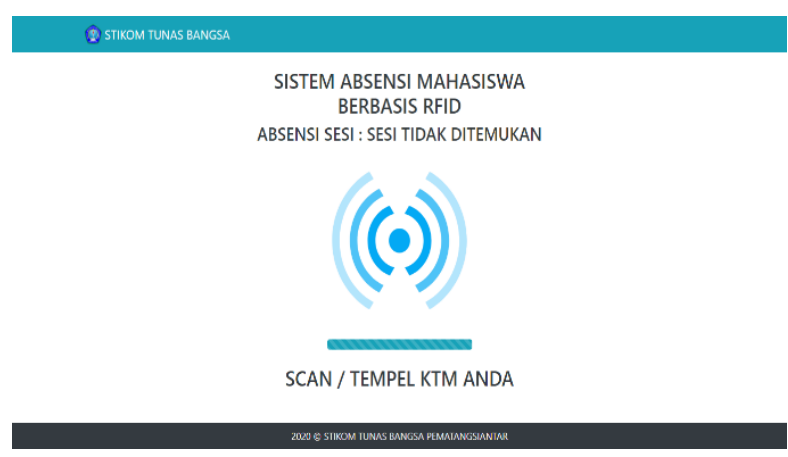

Figure 4 Student main page to see attendance verification

After the student attaches the student identification card, the system will read the RFID tag and will display student attendance information in the form of Nim, Name, Class and courses, as shown in Figure 5.



Figure 5 Student attendance information page

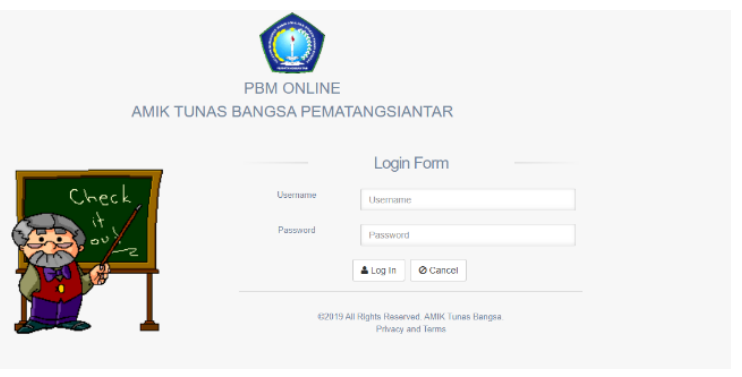

Figure 6 Login page
On the login page, it is shown in the Figure 6, used by lecturers and academics to enter the RFID-based attendance system. Lecturers and academics must enter an id and keyword so that they can enter the main page in Figure 7.

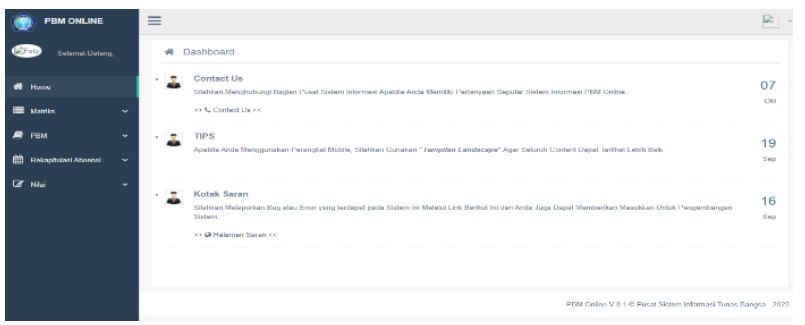

Figure 7 Lecturers page

On the main page shown in Figure 7, the lecturer will be responsible for viewing the teaching schedule that has been inputted by academics, this page is as in Figure 8, the lecturer can manage student attendance data following the teaching and learning process according to the schedule, this page is like in Figure 9 and see the recapitulation of student attendance from all schedules from the initial meeting to the final meeting of the teaching and learning process, this page is as in Figure 10. The features available on the lecturer will make it easier for lecturers to recapture student attendance in the teaching and learning process.

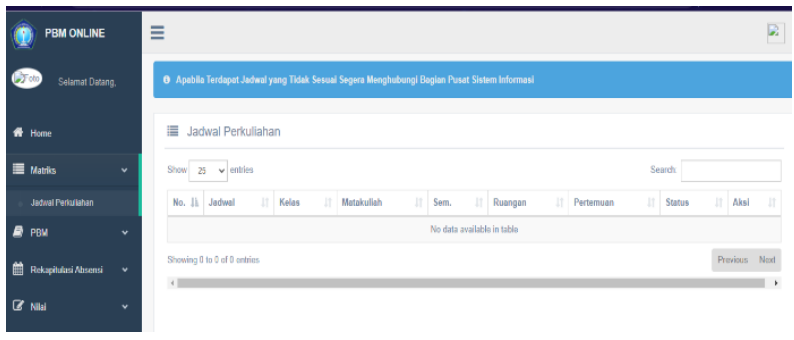

Figure 8 The lecturer teaching schedule page

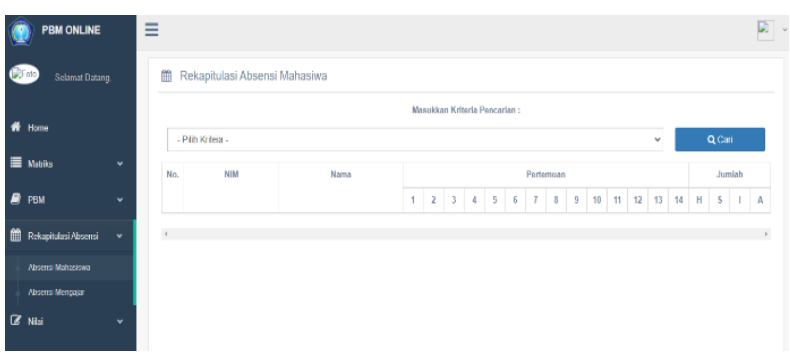

Figure 9 Student attendance page

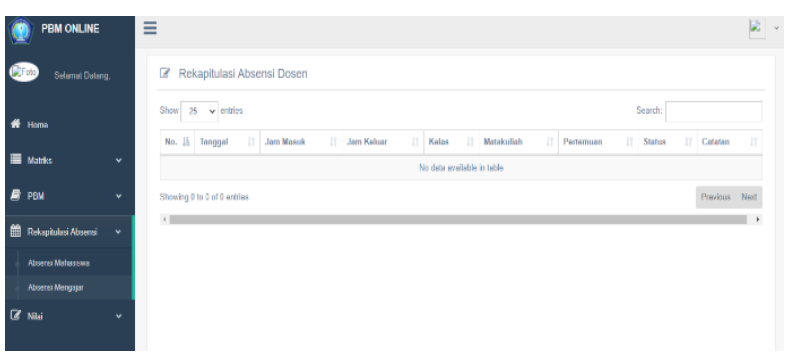

Figure 10 Student attendance recapitulation page 


\subsection{Create a Discussion}

The application of the RAD method combines iterative development and design prototyping [7]. The application of the RAD method is carried out to measure the effectiveness of time in making an attendance application based on RFID which refers to the development stages using the RAD model shown in Table 2 which presents the time needed to develop an RFID based attendance application.

Table 1. List of system test activities

\begin{tabular}{clll}
\hline Test ID & Desciption & Test Input & Remark \\
\hline 1 & RFID & KTM & Successful \\
2 & View Attandance & & Successful \\
3 & Login & Username,password & Successful \\
4 & Teaching Schedule & & Successful \\
5 & Attendance & Create, Read, Update & Successful \\
6 & Attendance Recapitulation & & Successful \\
\hline
\end{tabular}

Table 2. Timeline of Dutatani website development

\begin{tabular}{llll}
\hline Model & Stages & Duration & Team \\
\hline Interactive & Planning and analysis & 4 Weeks & 1 \\
RFID Tools & Implementation & 2 & 2 \\
System prototyping & Front End, Bank End dan Testing & 10 Weeks & 2 \\
Interactive & Integration & 6 Weeks & 3 \\
\hline
\end{tabular}

Based on Table 2, it is known that the time needed to develop an RFID based attendance system is 23 weeks or 110 days. This time is faster than the plans made earlier. One of the factors for the success of this RAD model is the relatively small developed system. The system integration process is carried out after all teams have finished their work. This integration process also requires a long time due to differences in some logic and programming styles that must be reset.

The results of the analysis of this study, the RAD method can accelerate the system development process with a faster time with good software quality and the method is suitable for small-scale application development [8] [9]. This method requires good communication so that the integration process can be carried out properly. The RAD method must also be continuously monitored and evaluated so that it can reduce risks due to different programming and logic from each software development team.

\section{CONCLUSION}

Based on the research conducted, it turns out that the RAD model can develop a system. The RAD model must still be monitored at every stage so that the speed of development work is as planned. The proposed system is effective and efficient in terms of technology and is easy to use, spends less time in the attendance process and reduces the workload in making attendance recaps for both lecturers and academics. RFID in higher education can speed up the attendance process and minimize errors in attendance. The RFID reader and the RFID tag used must be of good quality to produce a better reading process. The benefit of this research is that all attendance activities can be digitized and all data is stored in the database automatically. This application can produce work time savings, improve services, reduce errors and minimize the occurrence of human errors.

\section{ACKNOWLEDGMENTS}

We convey the acknowledgement to the Deputy for Strengthening Research and Development of the Ministry of Research and Technology/National Research and Innovation Agency for funding for Beginner Lecturer Research (PDP) in 2020.

\section{REFERENCES}

[1] F. Murti Dewanto, B. Agus Herlambang, A. Tri Jaka Harjanta, J. Informatika Fakultas Teknik dan Informatika UPGRIS, and J. Lontar No, "Pengembangan Sistem Informasi Absensi Berbasis Radio Frequency Identification (RFID) Terintegrasi dengan Sistem Informasi Akademik," J. Inform. J. Pengemb. IT, vol. 2, no. 2, pp. 90-95, 2017, [Online]. Available: http://www.ejournal.poltektegal.ac.id/index.php/inf ormatika/article/view/604.

[2] R. Qureshi, "The Proposed Implementation of RFID based Attendance System," Int. J. Softw. Eng. Appl., 
vol. 11, no. 3, pp. 59-69, 2020, doi: 10.5121/ijsea.2020.11304.

[3] S. Azad and B. Ray, "A Lightweight Protocol for RFID Authentication," Networked Intell. Syst. a Sustain. Futur., pp. 1-6, 2020, doi: 10.1007/978-3662-44893-9_10.

[4] Y. Kristyawan and A. D. Rizhaldi, "An Automatic Sliding Doors Using RFID and Arduino," Int. J. Artif. Intell. Robot., vol. 2, no. 1, pp. 13-21, 2020, doi: 10.25139/ijair.v2i1.2706.

[5] R. Delima, H. B. Santosa, and J. Purwadi, "Development of Dutatani Website Using Rapid Application Development," IJITEE (International J. Inf. Technol. Electr. Eng., vol. 1, no. 2, pp. 36-44, 2017, doi: 10.22146/ijitee.28362.

[6] V. Kralev and R. Kraleva, "Methods and tools for rapid application development," Proc. III Int. Sci.
Pract. Conf. "Methodology Mod. Res. (March 29, 2017, Dubai, UAE), vol. 1, no. 4 (20), pp. 21-24, 2017.

[7] K. Agarwal, a Agarwal, and C. Hiller, "Rapid applications development in Python," J. Comput. Sci. ..., no. April 2013, pp. 42-48, 2013, [Online]. Available:

http://dl.acm.org/citation.cfm?id=2458546.

[8] R. Naz and M. N. A. Khan, "Rapid applications development techniques: A critical review," Int. J. Softw. Eng. its Appl., vol. 9, no. 11, pp. 163-176, 2015, doi: 10.14257/ijseia.2015.9.11.15.

[9] O. G. Chiagozie and O. G. Nwaji, "Automatic Door Unit Radio Frequency Identification (RFID) Based Attendance System,” vol. 5, pp. 200-211, 2013. 